\title{
Formulation and evaluation of Norfloxacin gastro retentive drug delivery systems using natural polymers
}

\author{
*PD Thahera ${ }^{1}$, Ashok ${ }^{1}$, K Latha², T Shailaja2, S Nyamathulla ${ }^{3}$, MU Uhumwangho ${ }^{4}$ \\ ${ }^{1}$ M.M.U. College of Pharmacy, Ramanagaram, Banglore, India \\ ${ }^{2}$ G. Pulla Reddy College of Pharmacy, Mehidipatnam, Hyderabad-500 028, India \\ ${ }^{3}$ Department of Pharmacy, Faculty of Medicine, University of Malaya, Kuala Lumpur, Malaysia \\ ${ }^{4}$ Department of Pharmaceutics and Pharmaceutical Technology, Faculty of Pharmacy, University of Benin, Nigeria
}

\begin{abstract}
Gastric retentive floating drug delivery system (GFDDS) is enabled the prolonged continuous input of the drug to the upper parts of the gastrointestinal (GI) tract and improves the bioavailability of medications with narrow absorption window. The design of the delivery system is based on the controlled release formulation with floating and swelling features in order to prolong the gastric retention time of the drug delivery systems. In the present study norfloxacin as candidate, guar gum, sodium CMC, HPMC15 KM is studied along with other excipients like PVP K30 (binder), sodium bicarbonate microcrystalline cellulose were used in different concentrations to get the desired controlled release profile over a period of $12 \mathrm{hrs}$. All the formulations were evaluated for buoyancy lag time, duration of buoyancy, dimensional stability, drug content and in vitro drug release profile. Based on the in vitro studies carried out for the optimized formulation by dissolution the performance of the developed formulation promises to be efficient in controlling the drug release rate with the guar gum, a natural polymer.
\end{abstract}

Key Words: Gastrointestinal, Norfloxacin, Guar gum, Sodium CMC, HPMC 15KM, GRFDDS.

\section{INTRODUCTION}

There are different types of dosage forms, which are being administered through different routes. However oral route is the most preferred because of its better patient compliance. Majority of the drugs are having site-specific absorption in the G.I. tract and parameters like $\mathrm{pH}$ dependent solubility, stability and ionization of the drug in different portions of the G.I. tract influence the absorption. Gastric retention time is one of the important factors, which adversely affect the performance of these drugs when administered simply by an oral controlled drug delivery system (Chandel et al., 2012).

One of the most feasible approaches for achieving a prolonged and predictable drug delivery in the GI

\footnotetext{
*Corresponding Author:

Thahera Parveen D, Professor

Department of Pharmaceutics

M.M.U. College of Pharmacy

Ramanagaram, Bangalore, India

E-mail: tahera23in@gmail.com
}

tract is to increase the gastric residence time (GRT). Dosage forms with prolonged GRT are gastro retentive drug delivery systems which will provide prolonged release thereby allowing the drug to retain for a long time in the gastric region for increasing the bioavailability. This application is effective in delivery of soluble sparingly soluble and insoluble drugs. Gastric emptying of dosage forms is an extremely variable process and ability to prolong and control the emptying time is a valuable asset than conventional dosage forms. Several difficulties are faced in designing controlled release systems for better absorption and enhanced bioavailability (Sanjay and Sharma, 2003).

Norfloxacin is a synthetic chemotherapeutic antibiotic of the fluoroquinolone drug class. It is a secondgeneration fluoroquinolone antibacterial. It kills bacteria by interfering with the enzymes that cause DNA to rewind after being copied, which stops DNA and protein synthesis. It is a potential drug in treating various serious G.I diseases like gastritis, 
Table 1: Composition of Norfloxacin Floating Tablets.

\begin{tabular}{llllllllll}
\hline Excipients & FG1 & FG2 & FG3 & FS1 & FS2 & FS3 & FH1 & FH2 & FH3 \\
\hline Norfloxacin & 400 & 400 & 400 & 400 & 400 & 400 & 400 & 400 & 400 \\
Guar gum & 120 & 100 & 80 & - & - & - & - & - & - \\
SCMC & - & - & - & 120 & 100 & 80 & - & - & - \\
HPMC K15M & - & - & - & - & - & - & 120 & 100 & 80 \\
NaHCO & 100 & 100 & 100 & 100 & 100 & 100 & 100 & 100 & 100 \\
PVP-K-30 & 10 & 10 & 10 & 10 & 10 & 10 & 10 & 10 & 10 \\
Lactose & 25 & 45 & 65 & 25 & 45 & 65 & 25 & 45 & 65 \\
FLT (sec.) & 220 & 165 & 130 & 675 & 420 & 380 & 240 & 180 & 120 \\
TFT (hrs) & $>24$ & $>24$ & $>24$ & $>24$ & $>24$ & $>24$ & $>24$ & $>24$ & $>24$ \\
\hline
\end{tabular}

urinary tract infections, prostatitis and gonorrhea etc. The half-life is 4 hrs (Nelson et al., 2007).

The controlled gastric retention of solid dosage forms may be achieved by the mechanisms of mucoadhesion, flotation, sedimentation, expansion, modified shape system or by the simultaneous administration of pharmacological agent that delay gastric emptying (Shweta et al., 2005).

\section{MATERIALS AND METHODS}

\section{Materials}

Norfloxacin (Gift sample of $\mathrm{M} / \mathrm{s}$. Micro Labs, Bangalore) is a broad-spectrum antibiotic that is active against both Gram-positive and Gramnegative bacteria. Guar gum, HPMC $15 \mathrm{KM}$ (gift sample of Ontop pharmaceuticals, Bangalore) occurs as odorless or nearly odorless, white to yellowish-white powder with a bland taste used as suspending agent; tablet binder; tablet disintegrant; viscosity increasing agent, sustained-release matrix tablets. Hypromellose used as coating agent; film-

Table 2: Evaluation of flow properties of blend.

\begin{tabular}{llll}
\hline Formulations & $\begin{array}{l}\text { Angle of } \\
\text { repose }\end{array}$ & $\begin{array}{l}\text { Carr's index } \\
\text { (\%) }\end{array}$ & $\begin{array}{l}\text { Hausner's } \\
\text { ratio }\end{array}$ \\
\hline API & 46 & 35 & 1.4 \\
FG1 & 31 & 17 & 1.14 \\
FG2 & 33 & 20 & 1.16 \\
FG3 & 35 & 18 & 1.18 \\
FS1 & 33 & 17 & 1.14 \\
FS2 & 34 & 19 & 1.12 \\
FS3 & 32 & 16 & 1.11 \\
FH1 & 32 & 17 & 1.13 \\
FH2 & 34 & 20 & 1.12 \\
FH3 & 33 & 18 & 1.14 \\
\hline
\end{tabular}

former; rate-controlling polymer for sustained release; stabilizing agent; suspending agent; tablet binder; viscosity-increasing agent. Sodium carboxy methyl cellulose acts as coating agent; stabilizing agent; suspending agent; tablet and capsule disintegrant; tablet binder; viscosity-increasing agent; water-absorbing agent. Sodium bicarbonate, Lactose, PVP K30, Magnesium stearate, talc were purchased from S.D fine chemicals, Mumbai, used as effervescent, channeling agent, binder, lubricant and glidant respectively. Hydrochloric acid was purchased from Qualigens Fine Chemicals.

\section{Method}

All the ingredients were accurately weighed and passed through mesh \# 60. In order to mix the ingredients thoroughly drug and polymer were blended geometrically in a mortar and pestle for 15 min, then PVP K30, lactose and sodium bicarbonate, talc and magnesium stearate were mixed in polythene bag. After thoroughly mixing these ingredients, the powder blend was passed through \#44 mesh. Tablets were compressed on a single punch tablet machine (Cadmach, India) using $8 \mathrm{~mm}$ flat round punches. Total weight of the tablet is 670 $\mathrm{mg}$, containing $400 \mathrm{mg}$ of norfloxacin in each tablet as given in Table 1 .

\section{Pre-compression Parameters}

Tablets are evaluated for pre-compression parameters like angle of repose, bulk density, tapped density, Carr's index and values are tabulated in Table 2 .

Angle of Repose: Angle of repose has been defined as the maximum angle possible between the surface of pile of powder and horizontal plane and was 
Table 3: Evaluation of Norfloxacin GFDDS with guar gum, sodium CMC, HPMC 15 KM.

\begin{tabular}{lllll}
\hline Formulation & Weight $^{\mathbf{a}} \mathbf{( m g )}$ & Drug content $^{\mathbf{a}} \mathbf{( \% )}$ & Hardness $\left.^{\mathbf{a}} \mathbf{( K g} / \mathbf{c m}^{\mathbf{2}}\right)$ & Friability $^{\mathbf{b}} \mathbf{( \% )}$ \\
\hline Marketed & $515.00+1.36$ & $98.62+0.18$ & $10.2+0.32$ & 0.06 \\
FG1 & $670.00+1.46$ & $99.24+1.54$ & $5.82+0.49$ & 0.45 \\
FG2 & $670.00+1.28$ & $99.74+0.97$ & $5.14+0.24$ & 0.32 \\
FG3 & $670.00+1.37$ & $99.94+0.48$ & $5.06+0.56$ & 0.26 \\
FS1 & $670.00+0.56$ & $99.34+0.54$ & $6.02+0.49$ & 0.38 \\
FS2 & $670.00+0.18$ & $99.66+0.86$ & $5.94+0.24$ & 0.30 \\
FS3 & $670.00+0.47$ & $98.25+0.68$ & $5.30+0.56$ & 0.27 \\
FH1 & $670.00+1.46$ & $98.67+0.54$ & $6.82+0.49$ & 0.22 \\
FH2 & $670.00+1.28$ & $99.65+0.97$ & $5.14+0.54$ & 0.26 \\
FH3 & $670.00+1.37$ & $98.25+0.58$ & $6.06+0.36$ & 0.31 \\
\hline
\end{tabular}

a: Mean +S.D., $\mathrm{n}=10$ tablets , $\mathrm{b}: \mathrm{n}=10$ tablets

performed to determine the flow rate of powder (Banker et al., 1991 and Jain et al., 2012). The method used is the funnel method. The powder mass was allowed to flow through the funnel orifice kept vertically to a plane paper kept on the horizontal surface, giving a heap angle of powder on paper. The angle of repose was calculated by substituting the values of the base radius ' $r$ ' and pile height ' $h$ ' in the following equation:

$\theta=\tan ^{-1}\left(\frac{h}{r}\right)$

Bulk Density: Bulk density was obtained by dividing the mass of powder by the bulk volume in $\mathrm{cm}^{3}$. The sample of about $50 \mathrm{~cm}^{3}$ of powder, previously been passed through a standard sieve no. 20 , was carefully introduced into a $100 \mathrm{ml}$ graduated cylinder. The cylinder was dropped on to hard wood surface three times from a height of 1 inch. The bulk density of each formulation was then obtained by dividing the weight of sample in grams by the final volume in $\mathrm{cm}^{3}$ of the sample contained in the cylinder. It was calculated by using equation given below:

$L B D=\frac{\text { weight of the powder }}{\text { volume of the packing }}$

Tapped density: The tapped density was obtained by dividing the mass of powder by tapped volume in $\mathrm{cm}^{3}$. The sample of about $50 \mathrm{~cm}^{3}$ of powder, previously been passed through a standard sieve no.20, is carefully introduced in to a $100 \mathrm{ml}$ graduated cylinder. The cylinder was dropped on to hard wood surface hundred times from a height of 1 inch. The tapped density of each formulation was then obtained by dividing the weight of sample in grams by the final tapped volume in $\mathrm{cm}^{3}$ of the sample contained in the cylinder. It was calculated by using equation given below:

$T B D=\frac{\text { weight of the powder }}{\text { tapped volume of the packing }}$

Carr's index: Carr's index is an indirect method of measuring powder flow from bulk densities (Martin et al., 1994). The percentage compressibility of a powder was a direct measure of the potential powder arch or bridge strength and stability. Carr's index of each formulation was calculated to equation given below

$\operatorname{la}-C I(\%)=\left[\left(T B D-\frac{L B D}{T B D}\right)\right] \times 100$

Post compression parameters: Post compression quality control tests like tablet thickness, diameter, hardness, friability, uniformity of weight, content uniformity of drug (IP, 1996; Lachman et al., 1991) as

Table 4: \% Cumulative drug released from GFDDS containing varying concentrations of Guar gum.

\begin{tabular}{ccccc}
\hline \multirow{2}{*}{$\begin{array}{c}\text { Time } \\
\text { (hrs) }\end{array}$} & \multicolumn{4}{c}{ \% Cumulative drug released ( \pm S.D.) } \\
\cline { 2 - 5 } & Marketed & FG1 & FG2 & FG3 \\
\hline 1. & $19.02 \pm 0.48$ & $17.57 \pm 0.27$ & $19.82 \pm 1.64$ & $14.65 \pm 0.10$ \\
2. & $39.23 \pm 1.62$ & $30.75 \pm 1.74$ & $27.78 \pm 0.53$ & $25.67 \pm 0.85$ \\
3. & $52.80 \pm 0.07$ & $49.56 \pm 0.87$ & $38.53 \pm 0.66$ & $36.75 \pm 1.29$ \\
4. & $65.92 \pm 1.67$ & $63.64 \pm 0.08$ & $49.78 \pm 1.38$ & $45.67 \pm 0.17$ \\
5. & $83.71 \pm 1.86$ & $74.30 \pm 1.72$ & $58.68 \pm 1.45$ & $57.84 \pm 0.10$ \\
6. & $99.12 \pm 0.87$ & $85.40 \pm 1.55$ & $69.96 \pm 0.78$ & $64.65 \pm 0.16$ \\
7. & -- & $89.92 \pm 2.40$ & $82.42 \pm 0.05$ & $69.96 \pm 0.94$ \\
8. & -- & $97.41 \pm 0.52$ & $90.53 \pm 1.75$ & $77.76 \pm 1.64$ \\
9. & -- & -- & $94.13 \pm 1.19$ & $84.48 \pm 0.08$ \\
10. & -- & -- & $100.12 \pm 2.75$ & $91.24 \pm 0.71$ \\
11. & -- & -- & -- & $95.16 \pm 0.08$ \\
12. & -- & -- & -- & $99.87 \pm 1.54$ \\
\hline
\end{tabular}


Table 5: \% Cumulative drug released from GFDDS containing varying concentrations of sodium CMC.

\begin{tabular}{ccccc}
\hline \multirow{2}{*}{$\begin{array}{c}\text { Time } \\
\text { (hrs) }\end{array}$} & \multicolumn{4}{c}{ \% Cumulative drug released ( \pm S.D.) } \\
\cline { 2 - 5 } & Marketed & FS1 & FS2 & FS3 \\
\hline 1. & $19.02 \pm 0.48$ & $18.70 \pm 2.17$ & $17.37 \pm 1.64$ & $16.20 \pm 2.10$ \\
2. & $39.23 \pm 1.62$ & $36.52 \pm 1.74$ & $29.1 \pm 0.53$ & $29.60 \pm 0.85$ \\
3. & $52.8 \pm 0.07$ & $47.90 \pm 0.87$ & $37.09 \pm 0.56$ & $35.4 \pm 1.09$ \\
4. & $65.92 \pm 1.67$ & $59.67 \pm 0.16$ & $48.60 \pm 0.28$ & $43.64 \pm 0.77$ \\
5. & $83.71 \pm 1.86$ & $72.71 \pm 0.22$ & $61.24 \pm 0.25$ & $58.40 \pm 2.74$ \\
6. & $99.12 \pm 0.87$ & $87.63 \pm 0.55$ & $78.24 \pm 0.28$ & $65.74 \pm 2.16$ \\
7. & -- & $98.34 \pm 1.48$ & $83.36 \pm 0.98$ & $79.80 \pm 1.04$ \\
8. & -- & -- & $93.13 \pm 0.35$ & $87.26 \pm 0.54$ \\
9. & -- & -- & $98.95 \pm 1.76$ & $92.12 \pm 0.83$ \\
10. & -- & -- & -- & $99.56 \pm 0.89$ \\
\hline
\end{tabular}

well as other specific evaluation tests for GFDDS like floating lag time and total floating time \& release rate of drug are evaluated. Result is given in Table 3.

Tablet thickness and Diameter: Thickness and diameter of tablets were important for uniformity of tablet size. Thickness and diameter were measured using Vernier calipers.

Hardness: This test is used to check the hardness of a tablet which may undergo chipping or breakage during storage, transportation and handling. In this five tablets were selected at random and the hardness of each tablet was measure with Monsanto hardness tester. The hardness is usually measured in terms of $\mathrm{kg} / \mathrm{cm}^{2}$.

Friability: The friability test was carried out in Roche friabilator to evaluate the hardness and stability instantly. Twenty tablets were weighed (Wo) initially and put in a tumbling and rotating apparatus drum. Then, they are subjected to fall from 6 inches height. After completion of 100 rotations, the tablets were again weighed $(w)$. The percent loss in weight or friability (f) was calculated by the formula given below:

$$
\text { Percent friability }=\frac{\text { Initial weight-Final weight }}{\text { Initial weight }} \times 100
$$

Uniformity of weight: This test is performed to maintain the uniformity of weight of each tablet which should be in the prescribed range, this is done by sampling and weighing 20 tablets at random and average weight is calculated. Not more
Table 6: \% Cumulative drug released from GFDDS containing varying concentrations of HPMC 15KM.

\begin{tabular}{ccccc}
\hline \multirow{2}{*}{$\begin{array}{c}\text { Time } \\
\text { (hrs) }\end{array}$} & \multicolumn{4}{c}{ \% Cumulative drug released ( \pm S.D.) } \\
\cline { 2 - 5 } & Marketed & FS1 & FS2 & FS3 \\
\hline 1. & $19.02 \pm 0.48$ & $18.70 \pm 2.17$ & $17.37 \pm 1.64$ & $16.20 \pm 2.10$ \\
2. & $39.23 \pm 1.62$ & $36.52 \pm 1.74$ & $29.10 \pm 0.53$ & $29.60 \pm 0.85$ \\
3. & $52.80 \pm 0.07$ & $47.90 \pm 0.87$ & $37.09 \pm 0.56$ & $35.40 \pm 1.09$ \\
4. & $65.92 \pm 1.67$ & $59.67 \pm 0.16$ & $48.60 \pm 0.28$ & $43.64 \pm 0.77$ \\
5. & $83.71 \pm 1.86$ & $72.71 \pm 0.22$ & $61.24 \pm 0.25$ & $58.40 \pm 2.74$ \\
6. & $99.12 \pm 0.87$ & $87.63 \pm 0.55$ & $78.24 \pm 0.28$ & $65.74 \pm 2.16$ \\
7. & -- & $98.34 \pm 1.48$ & $83.36 \pm 0.98$ & $79.80 \pm 1.04$ \\
8. & -- & -- & $93.13 \pm 0.35$ & $87.26 \pm 0.54$ \\
9. & -- & -- & $98.95 \pm 1.76$ & $92.12 \pm 0.83$ \\
10. & -- & -- & -- & $99.56 \pm 0.89$ \\
\hline
\end{tabular}

than two of the individual weights deviate from the average weight by more than the percentage show in the Table 3 and none deviate by more than twice the percentage The mean and standard deviation were determined.

Content Uniformity: This test is performed to maintain the uniformity of weight of each tablet which should be in the prescribed range according to the Indian Pharmacopoeia. The content uniformity test is mandatory for tablets whose average weight is below $50 \mathrm{mg}$. This test is performed by taking twenty tablets were selected randomly, weighed and powdered. A quantity of powdered tablet equal to $100 \mathrm{mg}$ of norfloxacin was dissolved in $0.1 \mathrm{~N} \mathrm{HCl}$ in $100 \mathrm{ml}$ volumetric flask. The so formed sample was diluted and the absorbance was measured at $278 \mathrm{~nm}$ using $0.1 \mathrm{~N} \mathrm{HCl}$ as blank and the $\%$ drug content were estimated using the following formula.

In vitro buoyancy determination: The floating characteristics of the GFDDS are essential, since they influence the in vivo behaviors of the drug delivery system. However there seemed to be no threshold value for the floating system to remain afloat under a physiological condition due to the latter's complication.

Floating Lag Time: The time taken by the tablet to emerge onto the surface of the liquid after adding to the dissolution medium simulated gastric fluid without pepsin, at $\mathrm{pH} 1.2$, temperature $37 \pm 0.5^{\circ} \mathrm{C}$, paddle rotation at $50 \mathrm{rpm}$ and $900 \mathrm{ml}$ as volume, it is measured using stopwatch. 
Table 7: Release kinetics of Norfloxacin GFDDS with guar gum, sodium CMC, HPMC 15KM.

\begin{tabular}{cccccc}
\hline \multirow{2}{*}{ Formulation } & \multirow{2}{*}{$\begin{array}{c}\text { Zero } \\
\text { order }\end{array}$} & First & Higuchi & \multicolumn{2}{c}{ Peppas } \\
\cline { 5 - 6 } & order & Matrix & r & N \\
\hline Marketed & 0.996 & 0.929 & 0.986 & 0.996 & 0.900 \\
FG1 & 0.971 & 0.911 & 0.992 & 0.988 & 0.751 \\
FG2 & 0.984 & 0.921 & 0.983 & 0.989 & 0.678 \\
FG3 & 0.975 & 0.932 & 0.997 & 0.995 & 0.778 \\
FS1 & 0.993 & 0.926 & 0.987 & 0.997 & 0.838 \\
FS2 & 0.989 & 0.908 & 0.978 & 0.991 & 0.822 \\
FS3 & 0.988 & 0.735 & 0.980 & 0.991 & 0.799 \\
FH1 & 0.992 & 0.910 & 0.968 & 0.968 & 0.708 \\
FH2 & 0.996 & 0.900 & 0.982 & 0.998 & 0.954 \\
FH3 & 0.994 & 0.919 & 0.955 & 0.976 & 0.803 \\
\hline
\end{tabular}

Total Floating Time: The time taken by the tablet to float constantly on the surface of the gastric fluid without pepsin, at $\mathrm{pH} 1.2$, temperature $37 \pm 0.5^{\circ} \mathrm{C}$, paddle rotation at $50 \mathrm{rpm}$ it is measured using stopwatch.

In vitro dissolution studies: Dissolution test was carried out using USP XXIV (model DISSO, M/s. Labindia) rotating paddle method (apparatus 2). The stirring rate was 50rpm. $0.1 \mathrm{~N}$ hydrochloric acid was used as dissolution medium $900 \mathrm{ml}$ and was maintained at $37 \pm 0.5^{\circ} \mathrm{C}$. Samples of $5 \mathrm{ml}$ were withdrawn at predetermined time intervals, filtered and replaced with $5 \mathrm{ml}$ of fresh dissolution medium. The collected samples were suitably diluted with dissolution fluid, wherever necessary and were analyzed for the norfloxacin at $278 \mathrm{~nm}$ by using a double beam UV spectrophotometer (Shimadzu2000). Each dissolution study was performed for three times and the mean values were taken tabulated and shown in Table 4-6 and Figure 2-4.

Drug release kinetics: The analysis of drug release mechanism from the pharmaceutical dosage form is an important but complicated process and it is practically evident in case of matrix systems. As model-dependent approach, the dissolution data are fitted to four popular release models such as a zeroorder, first order, Higuchi and peppas equations (Higuchi, 1963; Peppas, 1985; Ritger, 1987), which have been described in the literature. The order of drug release from matrix systems was studied by using Higuchi equation and Erosion equation. The value of $\mathrm{n}$ indicates the drug release mechanism. For a slab the value $\mathrm{n}=0.5$ indicates fickian diffusion
Table 8: Kinetic parameters of Norfloxacin GFDDS prepared from various concentrations of guar gum, Sodium CMC, HPMC 15 KM.

\begin{tabular}{cc}
\hline Formulation & $\mathbf{T}_{50 \%} \mathbf{( h r s )}$ \\
\hline Marketed & $3.18 \pm 0.540$ \\
FG1 & $3.81 \pm 0.125$ \\
FG2 & $4.01 \pm 0.186$ \\
FG3 & $4.56 \pm 0.168$ \\
FS1 & $3.23 \pm 0.104$ \\
FS2 & $4.23 \pm 0.066$ \\
FS3 & $4.50 \pm 0.168$ \\
FH1 & $4.53 \pm 0.104$ \\
FH2 & $5.59 \pm 0.460$ \\
FH3 & $7.05 \pm 0.168$ \\
\hline
\end{tabular}

T50\%: time taken to dissolve $50 \%$ of the drug

and values of $n$ between 0.5 and 1.0 or $n=1.0$ indicate non-fickian mechanism. In case of a cylinder $n=0.45$ instead of 0.5 , and 0.89 instead of 1.0. This model is used to analyze the release from polymeric dosage forms, when the release mechanism is not well known or when there is a possibility of more than one type of release phenomenon being involved.

Stability studies: Adequate stability data of the drug and its dosage form is essential to ensure the strength, safety, identity, quality, purity and in vitro release rates that they claim to have at the time of use (Nash and Waltes, 2000). A controlled release product should release a predetermined amount of the drug at specified time intervals, which should not change on storage. Any considerable deviation from the appropriate release would render the controlled release product useless. The in vitro and in vivo release rates of controlled release product may be altered by atmospheric or accelerated conditions such as temperature and humidity.

\section{RESULTS AND DISCUSSION}

In the present study, GFDDS of norfloxacin were prepared by using different polymers like guar gum, sodium CMC, HPMC 15KM as natural polymer, using sodium bicarbonate as gas generating agent, PVPK30 is used as a binding agent and lactose is used as diluent. GFDDS tablets were prepared by direct compression technique. Formulation was optimized by using different ratios of polymers, gas generating agent and diluents. The hardness of the prepared GFDDS of norfloxacin was found to be in the range of 4.8 to $6.82 \mathrm{~kg} / \mathrm{cm}^{2}$. The 


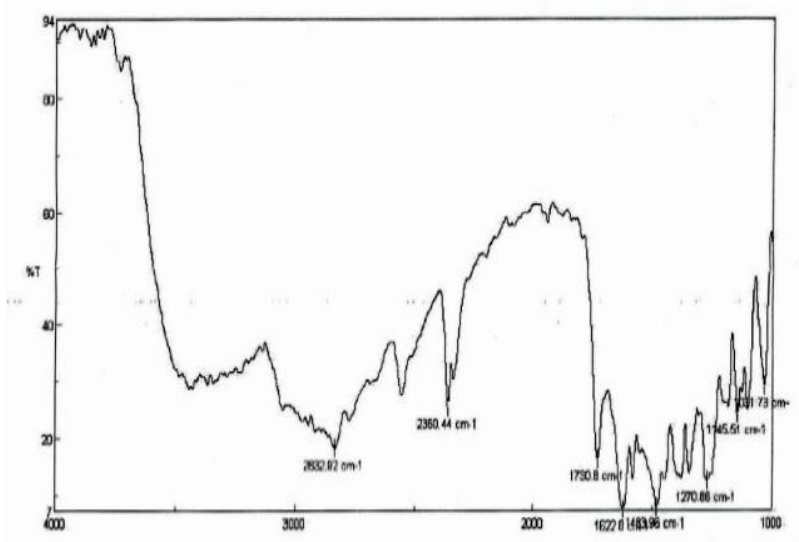

(a)

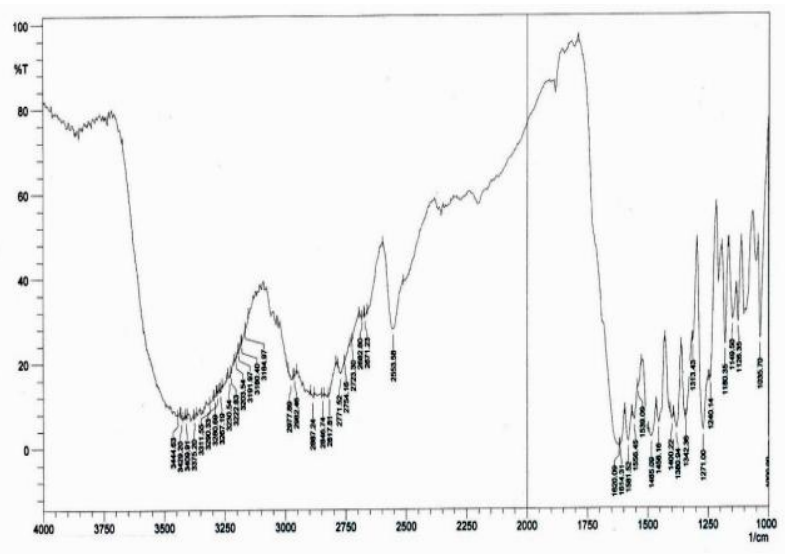

(c)

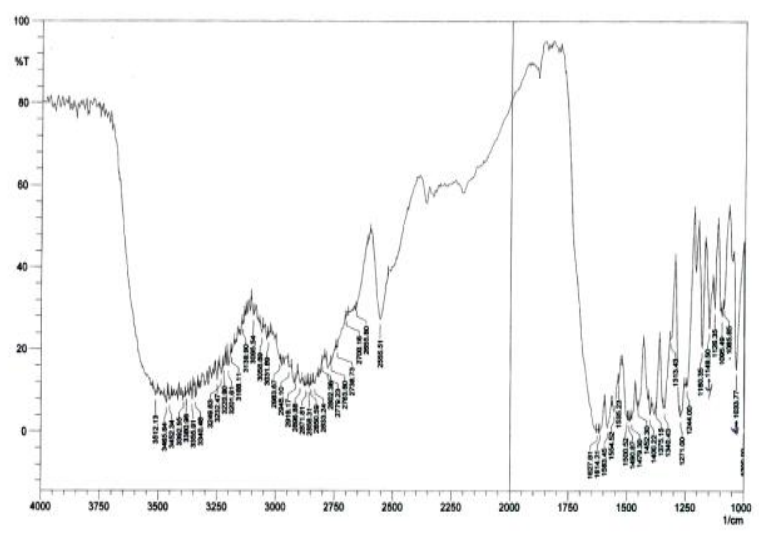

(b)

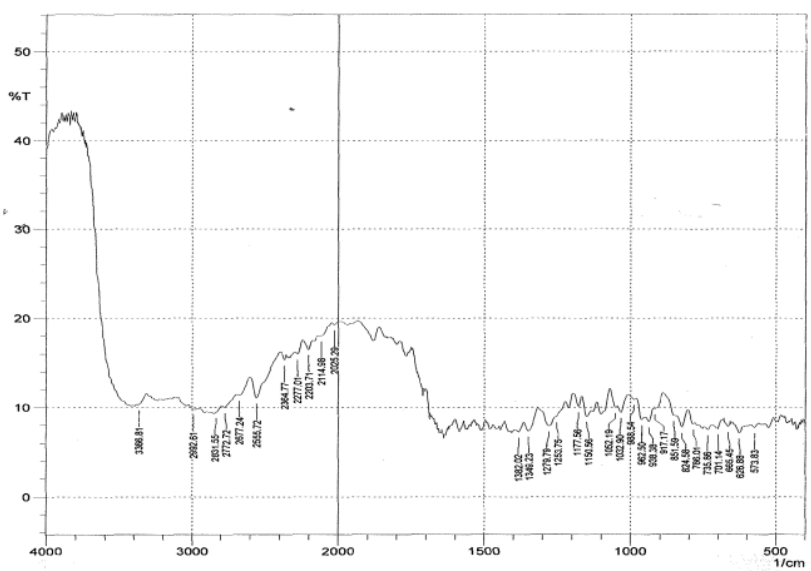

(d)

Figure 1: FTIR spctra of (a) Norfloxacin (b) Norfloxacin with guar gum (c) Norfloxacin with HPMC 15 KM (d) Norfloxacin with sodium CMC.

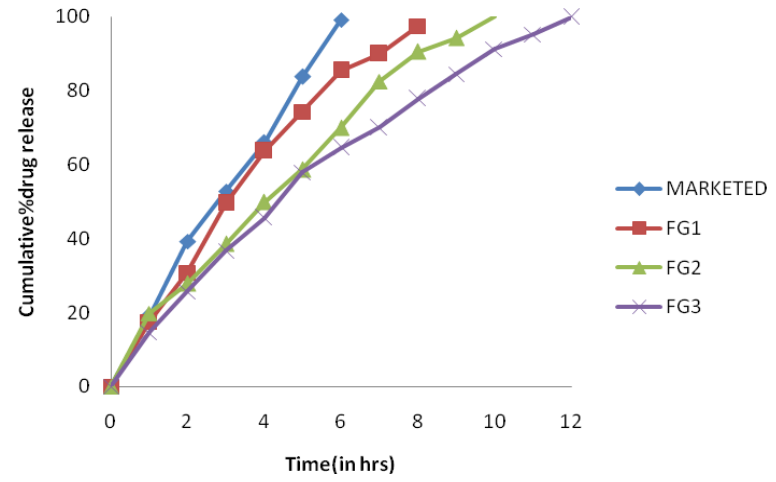

Figure 2: In vitro release profile of norfloxacin formulation FG1, FG2 \& FG3, with marketed product.

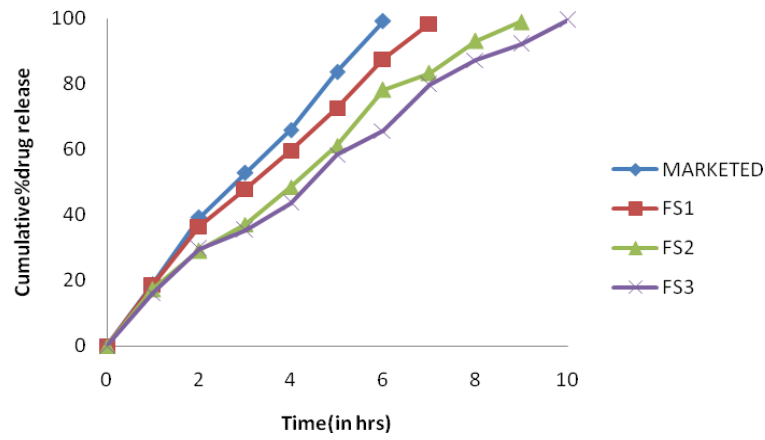

Figure 3: In vitro release profile of norfloxacin formulation FS1, FS2 \& FS3, with marketed product. 


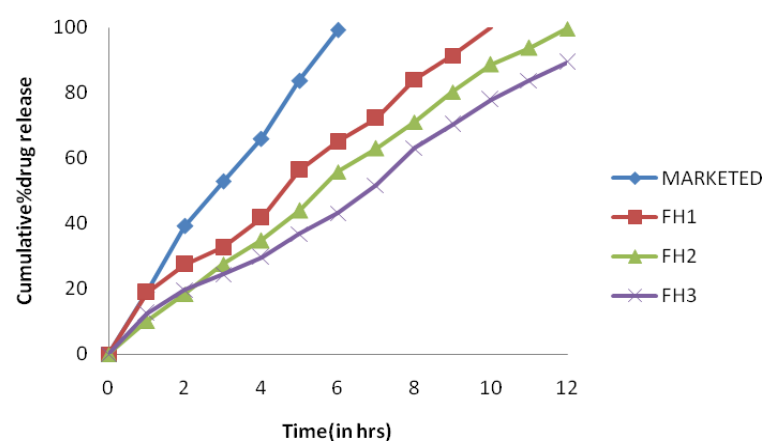

Figure 4: In vitro release profile of Norfloxacin formulation FH1, FH2 \& FH3, with marketed product.

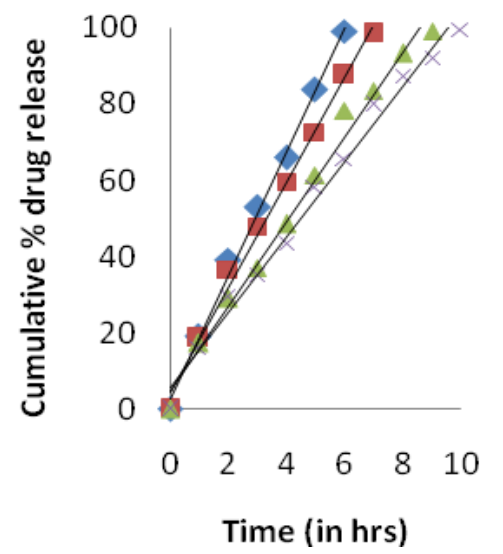

(i)

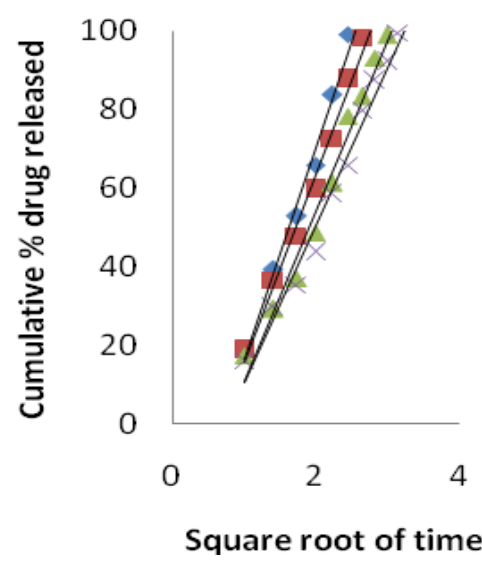

(iii)

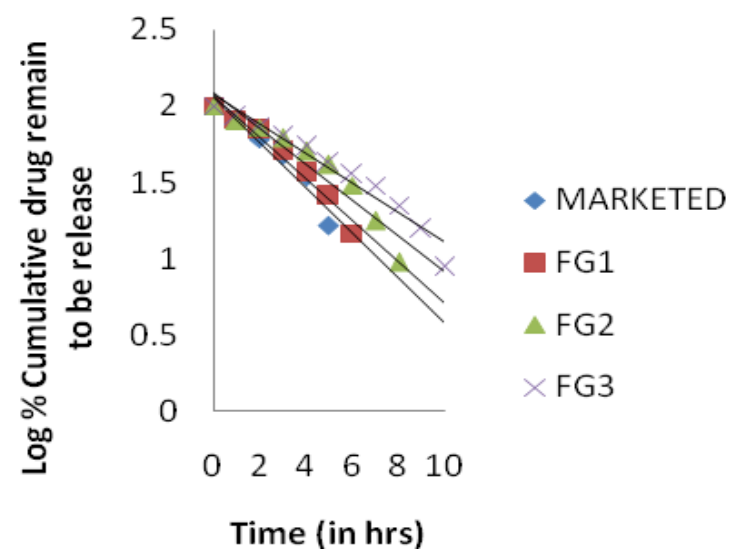

(ii)

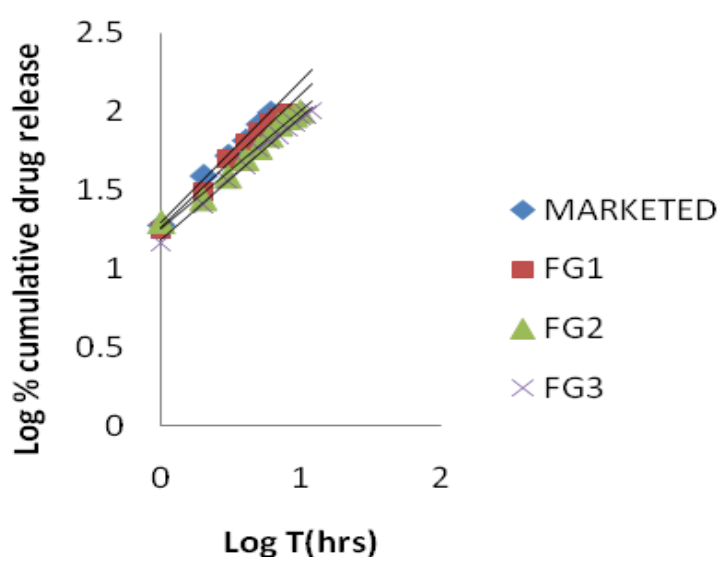

(iv)

Figure 5: Linear regression plots for the dissolution profiles of norfloxacin formulations by (i) Zero order release (ii) First order release (iii) Higuchi plot (iv) Peppas plot for FG1, FG2 \& FG3 with marketed product. 


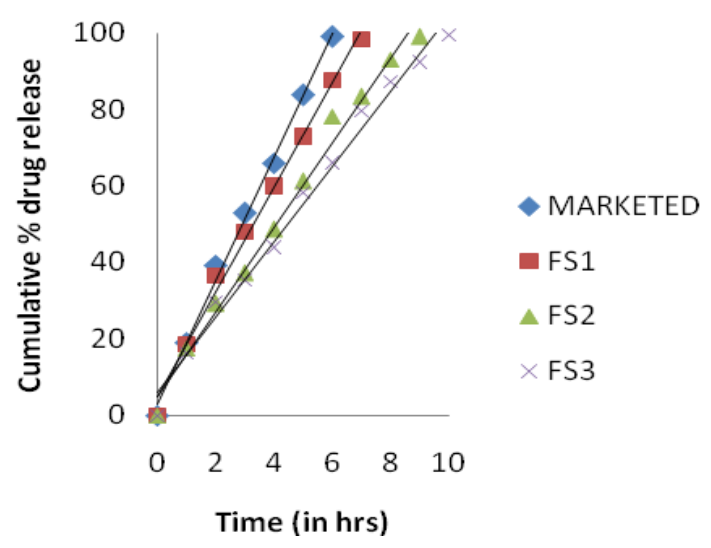

(i)

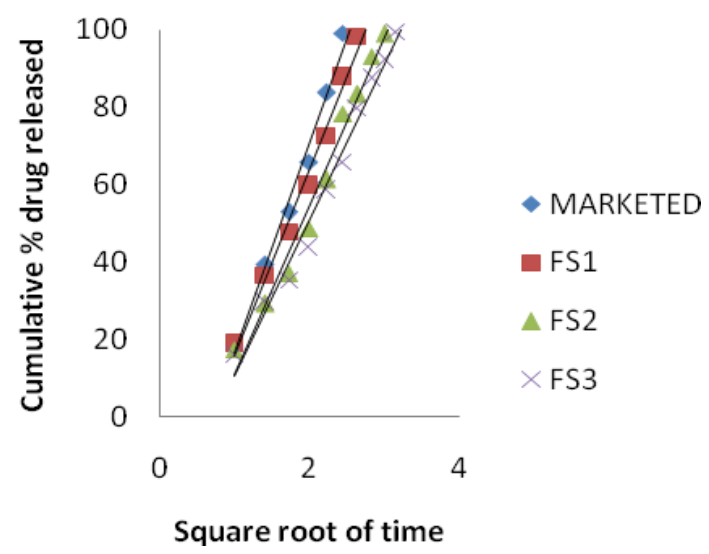

(iii)

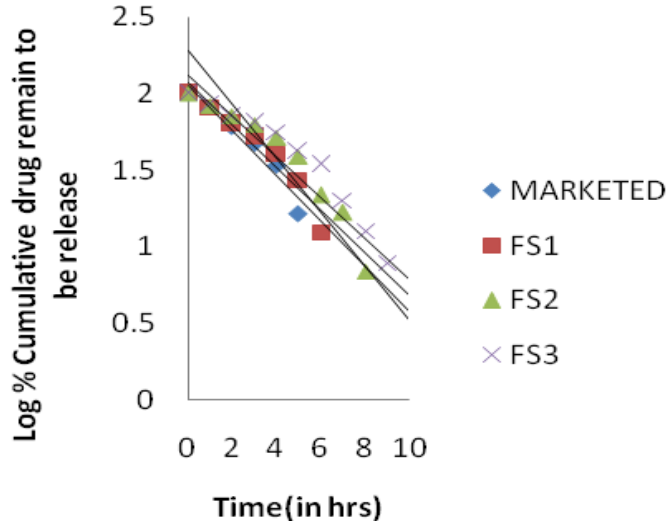

(ii)

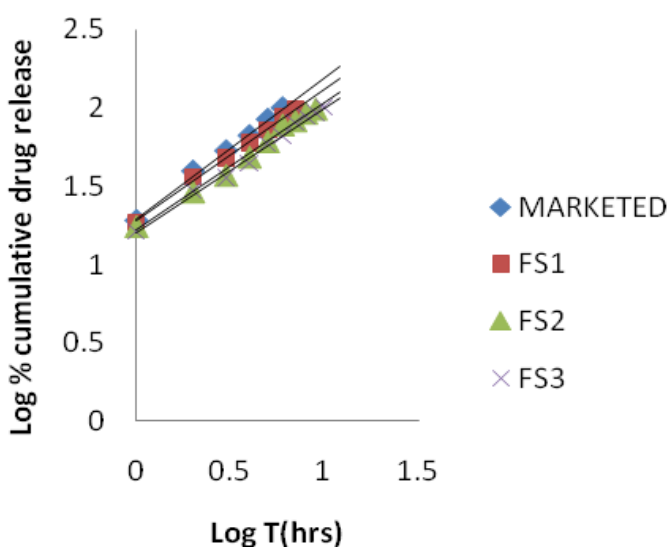

(iv)

Figure 6: Linear regression plots for the dissolution profiles of norfloxacin formulations by (i) Zero order release (ii) First order release (iii) Higuchi plot (iv) Peppas plot for FS1, FS2 \& FS3 with marketed product.

friability of all the tablets was to be less than $1 \%$ i.e. in the range of 0.22 to $0.56 \%$. All the prepared GFDDS tablets were evaluated for weight variation. Percent deviation from the average weight was found to be within the prescribed official limits. The drug content uniformity was examined as per I.P specification. All the batches of tablets were found to comply with uniformity of content test. FTIR spectras of pure norfloxacin, blend of polymers with drug were determined. Norfloxacin showed that the principle IR peaks 2832.92, 2360.44, 1730.8, 1622.81, 1483.96, 1270.86, 1145.51, $1031.73 \mathrm{Cm}^{-1}$. Norfloxacin with guar gum has shown 2833.24, 2360.48, 1627.81, 1479.30, 1271, 1149.50, $1033.77 \mathrm{Cm}^{-1}$. Norfloxacin with HPMC K15M has shown 2846.74, 1620.09, $1485.09,1271.00,1149.50,1035.70 \mathrm{Cm}^{-1}$. Norfloxacin with Sodium CMC has shown 1032.9, 1279.79, 2364.77, $2831.55 \mathrm{Cm}^{-1}$. Minor shifts were observed in between the pure drug and polymers (Figure 10-12). Floating lag time was observed that the range of 55 to 540 seconds and the tablet floats up to 24 hours for all the formulations. The results are given in Table 1.

Formulations FG1, FG2 and FG3 with guar gum exhibited $97.41,100.12$ and $99.87 \%$ of drug release in 8,10 and 12 hours respectively and the data is given in Table 4 and drug release profiles are shown in Figure 2. Formulations FS1, FS2 and FS3 with Sodium CMC exhibited $98.34,98.95$ and $99.56 \%$ of drug release in 7, 9 and 10 hours respectively and the data is given in Table 5 and drug release profiles are shown in Figure 3. Formulations FH1, FH2 and FH3 with HPMC K15M exhibited 100.02, 99.65 and $89.25 \%$ of drug release in 8,10 and 12 hours respectively and the data is given in Table 6 and drug 


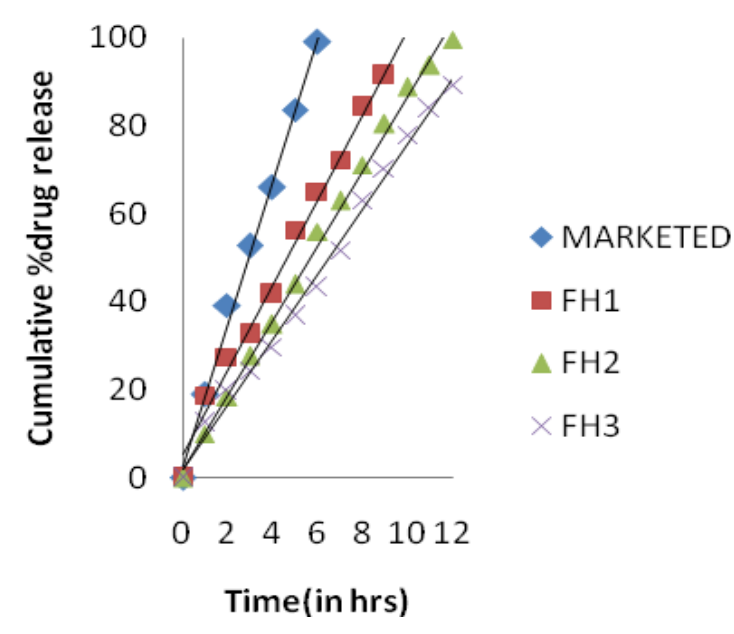

(i)

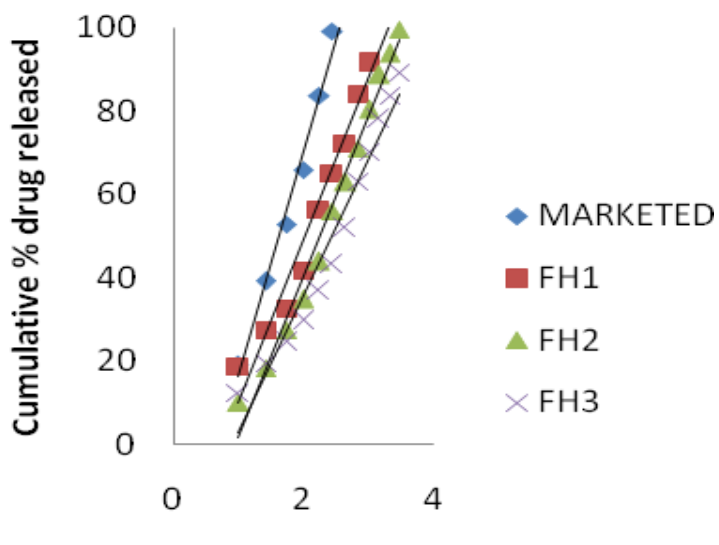

Square root of time

(iii)

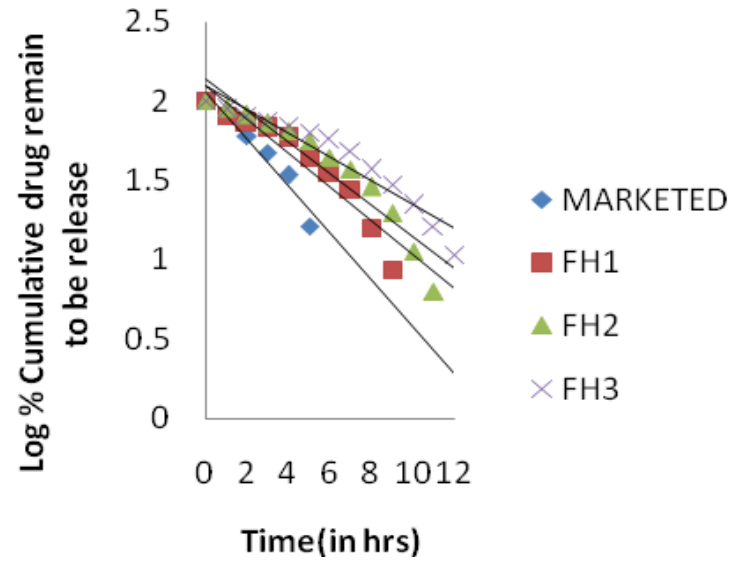

(ii)

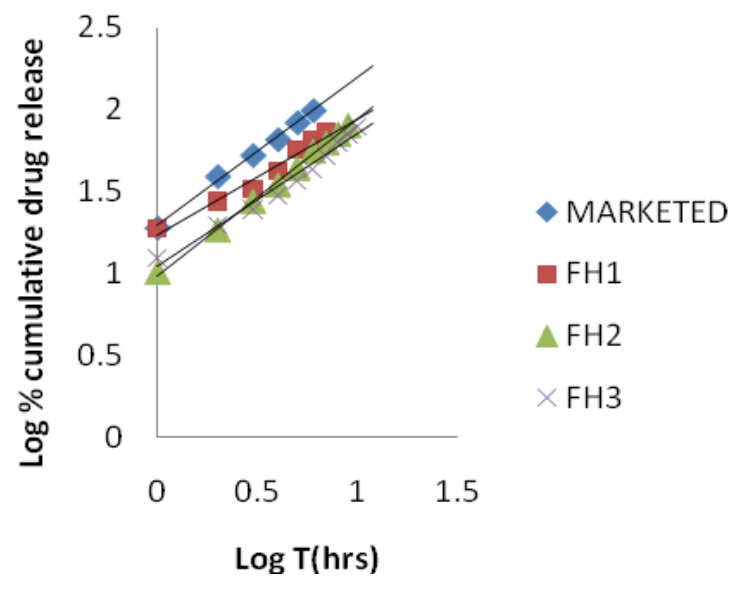

(iv)

Figure 7: Linear regression plots for the dissolution profiles of norfloxacin formulations by (i) Zero order release (ii) First order release (iii) Higuchi plot (iv) Peppas plot for FH1, FH2 \& FH3 with marketed product.

release profiles are shown in Figure 4. The amount of drug released for a particular drug polymer ratio was found to be in the order of SODIUM CMC > HPMCK15M> GUAR GUM.

The marketed product has shown release of 99.12 at the end of $6^{\text {th }}$ hour and the data is given in Table 4-6 and Figure 2-4. Formulation FG3 releases $99.87 \%$ of drug at the end of $12 \mathrm{hrs}$. The results of linear regression analysis of data including regression coefficient are summarized in Table 7 and Figure $5-7$. When the regression coefficient ' $r$ ' value of zero order and first order plots were compared, it was observed that the ' $r$ ' values of zero order were in the range of 0.97 to 0.99 whereas the ' $r$ ' values of first order plots were found to be in the range of 0.70 to 0.93 indicating drug release from all the formulations were found to follow zero order kinetics. The good fit of the Higuchi model to the dissolution profiles of all the formulations suggested that diffusion is the predominant mechanism limiting drug release since the ' $r$ ' values of Higuchis plots were nearer to unity. The in vitro dissolution data as log cum percent drug release versus log time were fitted to Korsmeyer equation (Krosmeyer et al., 1983), values of the exponent ' $n$ ' was found to be in the range of 0.678 to 0.900 indicating that the drug release is by non-fickian diffusion mechanism. 


\section{CONCLUSION}

Gastric Floating Drug Delivery (GFDD) systems of norfloxacin with shorter lag time can be prepared by direct compression method using guar gum, sodium $\mathrm{CMC}$, and $\mathrm{HPMC} 15 \mathrm{KM}, \mathrm{NaHCO}_{3}$ as gas generating agent and were found to extend the drug release over a period of 7 to $12 \mathrm{hrs}$ and the drug release decreased with decrease in polymer concentration. FG3 was considered as an ideal formulation which exhibited $99.87 \%$ of drug release in $12 \mathrm{hrs}$, and floating lag time of 130 seconds with a floating time of $24 \mathrm{hrs}$ and no drug-excipient interaction in the prepared formulations was confirmed by FTIR studies.

\section{REFERENCES}

Banker, G.S. and Anderson, N.R., In: Lachman, Liberman, L.H.A. and Kanig, J.L., Eds., (1991). The Theory and Practice of Industrial Pharmacy, $3^{\text {rd }} \mathrm{Ed}, 4^{\text {th }}$ Indian Reprint, Verghese Publishing House, Bombay, Pp. 317.

Chandel, A., Chauhan, K., Parashar, B., Kumar, H. and Arora, S. (2012). Floating drug delivery system: A better Approach, International Current Pharmaceutical Journal, Volume 1, Issue 5, Pages 110-115. [DOI]

Higuchi, T. (1963). Mechanism of sustained-action medication. Theoretical analysis of rate of release of solid drugs dispersed in solid matrices, J. Pharm. Sci. Volume 52, Pages 1145-1149. [DOI] PMid:14088963

Indian Pharmacopoeia, Vol. II. (1996). Govt of India, Ministry of Health \& Family Welfare, (A-80-84). Published by the Controller of Publication, Delhi, A-80-84.

Jain, N., Mandal, S., Banweer J. and Jain, S. (2012). Effect of superdisintegrants on formulation of taste masked fast disintegrating Ciprofloxacin tablets, International Current Pharmaceutical Journal, Volume 1, Issue 4, Pages 62-67. [DOI]
Korsmeyer, R.W., Gurny, R., Doelker, E.M., Buri, P. and Peppas, N.A. (1983) Mechanism of solute release from porous hydrophilic polymers, Int. J. Pharm. Volume 15, Pages 25-35. [DOI]

Lachman, L., Lieberman, H. A. and Kanig, J.L., Eds. (1991). "The Theory and Practice of Industrial Pharmacy", $3^{\text {rd }}$ Ed., $3^{\text {rd }}$ Indian Reprint, Verghese Publishing House, Bombay, Pages 297-300.

Martin, A., Bustamante, P. and Chun, A.H.C. (1994). Physical Pharmacy, $4^{\text {th }}$ Ed., Indian reprint, BI Waverly Pvt. Ltd., New Delhi, Pp. 444.

Nash and Waeltes. (2000). Pharma process validation, ICH guidelines on stability studies of dosage forms, $3^{\text {rd }}$ Edition revised, Pp. 129.

Nelson, JM.; Chiller, TM.; Powers, JH.; Angulo, FJ. (Apr 2007). "Fluoroquinolone-resistant Campylobacter species and the withdrawal of fluoroquinolones from use in poultry: a public health success story." Clin Infect Dis 44(7): 977-980. [DOI] PMid:17342653

Peppas, N.A. (1985) Analysis of Fickian and non-fickian drug release from polymer. Pharm. Acta Helv, Volume 60, Pages 110-111. PMid:4011621

Ritger, P.L. and Peppas, N.A. (1987). A simple equation for description of solute release II. Fickian and anomalous release from swellable devices, Journal of Controlled Release, Volume 5, Pages 37-42. [DOI]

Sanjay, G. and Sharma, S. (2003) Gastro retentive drug delivery systems, Drug delivery Oral, Pages 160-166.

Shweta, A., Javed, A., Alka, A., Roop, K.K. and Sanjula, B. (2005). Floating drug delivery system: A Review, AAPS Pharma Sci. Tech, Volume 6, Issue 3, Pages E372-E390. PMid:16353995 PMCid:2750381 